\title{
The Role of Genetically Modified Crops to Agricultural Advancement
}

\author{
Temesgen Begna* \\ Chiro National Sorghum Research and Training Center P. O. Box 190, Chiro, Ethiopia
}

*Corresponding Authors: Temesgen Begna, Chiro National Sorghum Research and Training Center P. O. Box 190, Chiro, Ethiopia

\begin{abstract}
Genetic engineering is not just an extension of conventional breeding. Genetic modification in plants was first recorded 10,000 years ago in Southwest Asia where humans' first bred plants through artificial selection and selective breeding. Since then, advancements in agriculture science and technology have brought about the current genetic modification of crop revolution. Genetically modified crops are promising to mitigate current and future problems in commercial agriculture, with proven case studies in world. Progress in crop improvement is limited by the ability to identify favourable combinations of genotypes and management practices given the resources available to search among possible combinations in the target population of environments. Crop improvement can be viewed as a search strategy on a complex $G \times M \times E$ adaptation. The advantages of genetic engineering result mainly from the ability to circumvent the shortcomings of sexual reproduction. Improvement affects only the targeted trait (no segregation), so there is less need for large populations and multiple generations of selection. sterile and vegetative propagated crops are as readily treatable by this approach as fertile crops. Likewise, the limitations of genetic engineering are complemented by the strengths of conventional methods, in that the new technology can usually target only simple, singlegene traits; it is expensive and technically demanding. Genetic engineering is the improvement program which enhances the efficiency of crop improvement relative to conventional phenotypic selection by changing the focus from the paradigm of identifying superior varieties to a focus on identifying superior combinations of genetic regions and management systems. Plant biotechnology facilitates the farming of crops with multiple durable resistances to pests and diseases, particularly in the absence of pesticides. Likewise, transgenes or marker-assisted selection may assist in the development of high yielding crops, which will be needed to feed the world and save land for the conservation of plant biodiversity in natural habitats. Hence, crops should be engineered to meet the demands and needs of consumers. The genetic base of crop production can be preserved and widen by an integration of biotechnology tools in conventional breeding. Similarly targeting specific genotypes to particular cropping systems may be facilitated by understanding specific gene-byenvironment interaction(s) with the aid of molecular research. High quality crops with improved nutritional and health characteristics as well as other aspects of added-value may be obtained through multidisciplinary co-operation among plant breeders, biotechnologists, and other plant scientists. Generally, the world population is increasing alarmingly, but productivity is reduced because of several production challenges. Hence, conventional plant breeding method alone cannot address the serious challenges that world facing. Therefore, in order to overcome the food security problems, conventional plant breeding should be assisted and integrated with various biotechnology developments to hasten the crop genetic improvements. To ensure the rapid and advanced agricultural developmental within short period of time, the incorporation of genetic engineering in plant breeding is very relevant in the future world. Genetic engineering is not about the replacement of conventional breeding rather than integrating with it in order to make further improvement. There are various challenges in relation to the application of genetic modifications because of its costs in large scale utilization especially in developing countries. The integration of genetic engineering into conventional breeding program is an optimistic strategy for crop improvement in the future.
\end{abstract}

Keywords: Genetic Modification; Recombination; Crops; Improvement

\section{INTRODUCTION}

Genetic engineering is the process of genetic modification of organisms through transferring genetic material from one organism to another organism in order to change an organism's characteristics to the desired traits. A genetically modified organism (GMO) is an organism (plant, animal or microorganism) whose genetic material has been altered using gene or cell techniques of modern biotechnology (Ssekyewa, C. and Muwanga, M.K., 2009). Genetic engineering or recombinant DNA 
(rDNA) technology involves artificial transfer of genes or gene fragments from one organism to another to produce novel traits in the recipient living organism. Genetic modification (GM) is the area of biotechnology which concerns itself with the manipulation of the genetic material in living organisms, enabling them to perform specific functions (Zhang C et al., 2016). Genetic engineering is using recombinant DNA technology to change the genetic make-up of an organism for the production of intended organisms with desired traits. Genetically modified crops are known as genetically engineered or bio-engineered crops and these are crops produced from organisms that have had changes introduced into their DNA using the methods of genetic engineering. Genetic engineering techniques allow the introduction of new traits from one organism to another organism for significant improvement over the previous existing traits and greater control over traits than previous methods such as selective breeding and mutation breeding (Lawlor, D.W., 2013).

Genetic modification involves the transfer of genetic material between species and which was developed using microorganisms in the 1970s and applied to plants and animals during the middle and late 1980s. First attempts to genetically modify crops were undertaken in the 1980s and were applied to tobacco, not to food plants. The first genetically modified food that came into the market was the Flavr Savr tomato in 1994 and which was engineered to have extended shelf-life by inserting an antisense gene that delayed ripening (Lawlor, D.W., 2013). This tomato was not a commercial success, probably due to lack of consumer acceptance, and was eventually withdrawn from the market. Then followed genetically modified crops like potato, Bt. maize, Bt cotton, glyphosphate tolerant soybeans and golden rice in the year 2000 (James, 2011). Genetic modifications have primarily focused on highly demanded crops for resistance to pathogens and herbicides for better nutrient profiles.

Genetically modified crops are the most predominant genetically modified organisms and which introduced into the environment for food and feed production and to a lesser degree for industrial applications, and are controversial for this reason (Lee, 2009). The transferred gene(s) from the donor organism then functions in a specific way in the host organism, altering both its genetic makeup and its biological behavior. There is usually more than one donor organism, as DNA sequences from bacteria or viruses are needed to facilitate the transfer of genetic material (as vectors), as control mechanisms (promoter genes) and as markers to demonstrate that the genetic modification has been successful (antibiotic and herbicide resistance). Agriculture is the major economic backbone of the world in improving the livelihood the population and contributing the highest growth domestic product of the world. Global demand for food is increasing with the growing world population and the arable land also decreased. However agricultural productivity is affected by diverse biotic and abiotic constraints which significantly and adversely restrict the crop productivity to below its yield potential. Therefore, global agricultural productivity must increase in order to meet the increasing food demands (FAO, 2013).

Population growth, particularly in countries with developing economies, will result in the need for a $70 \%$ increase in food production by the year 2050 making the significant improvement of agricultural productivity in the next several decades (Delaney, 2015). This revealed that the impossibility to feed the world population growth only through conventional crop yield improvement. Hence, overcoming all these difficult challenges will be harder in the absence international integration of plant biotechnology into plant improvement to increase agricultural productivity through addressing the problem of yield reduction (Begna T, 2020). The practice of improving crop production system with advanced breeding techniques play an important role to alleviate poverty and raise the living standards of the peoples by obtaining better yields of different crops (Gruhn et al., 2000). There are possibilities to improve the desired traits through conventional breeding methods in the presence of genetic diversities. However, there are several challenges to make the significant improvement on the crop through conventional breeding. In the practice of crop improvement, conventional breeding program involves crossing whole genomes followed by selection of the superior recombinants from among the several segregation products. Indeed, such a procedure is laborious and time consuming, involving several crosses, several generations, and careful phenotypic selection, and the tight linkage of the undesired loci with the desired loci may make it further difficult to achieve the desired objective.

Conventional breeding is almost always based on phenotypic variation of the crops, which is affected by environments (non-heritable components) and crop improvement cycle takes long time. In 
conventional plant breeding program, genes can be transmitted only by crossing in the same or closely related species, however genetic engineering has allowed genetic material to be transferred between completely unrelated crop species in addition closely related crop species. Hence breeders can incorporate characteristics that are not normally available within a species. The modified organisms exhibit properties that would be impossible to obtain by conventional breeding techniques. Modern biotechnology makes plant breeding programs more effective in two important ways. Firstly it allows transfer of specific genes, incorporating into the new variety only those traits that are wanted. This makes the process of trait transfer faster, more exact, cheaper and less likely to fail than traditional cross breeding methods. Secondly, it gives breeders the freedom to incorporate genes from unrelated species into the target plant, a possibility that is unprecedented in plant breeding. Transgenic methods have been employed over the last 15 years in a number of important crop plants such as maize, cotton, soybean, oilseed rape and a variety of vegetable crops like tomato, potato, cabbage and lettuce. Genetically modified crops have been widely adopted, with approximately 114 million ha cultivated in 23 countries worldwide in 2007(James, 2011).

Genetically modified crops have potential advantages in terms of increasing agricultural productivity and reducing the need for environmentally harmful pesticides. Genetically modified crops are designed to provide a higher nutritional value to food, increasing yield, tolerance to environmental stresses and protect crops against pests. Genetic modification of crops has enabled plant breeders to modify plants in novel ways and has the potential to overcome important problems of modern agriculture. Introduction of genes into plants has been made possible using agrobacterium as a biological vector, and direct gene transfer techniques. Agrobacterium-based methods are more efficient as compare to other gene transferring methods but have the disadvantages that are not applicable in every plant species (Christou, 1995). Thus, some have turned to genetically engineered crops as a way to meet the demands of a changing world. The objective/s of the paper was to review the role of genetic engineering in agricultural crop improvement and the efficiency of crop improvement relative to conventional breeding program to produce new superior varieties for desirable agronomic characteristics.

\section{Role of Genetically Engineered Crops to Agricultural DeVElopMent}

\subsection{Historical Development of Genetically Modified Foods}

The process of conventional plant breeding in which organisms with desired traits or genes are used to breed the next generation and organisms lacking the trait are not bred is a precursor to the modern concept of genetic modification. With the discovery of DNA in the early 1900s and various advancements in the genetic techniques through the 1970s it became possible to directly alter the DNA and genes within food (Jackson, 1972). Genetic modification involves the transfer of genetic material between species which was developed using microorganisms in the 1970s and applied to plants and animals during the middle and late 1980s. First attempts to genetically modify crops were undertaken in the 1980s using an antibiotic resistant tobacco plant, not to food plants. Genetically modified microbial enzymes were the first application of genetically modified organisms in food production. Cheese was made using the enzyme complex Rennet which was extracted from the cow's stomach lining. Scientists modified bacteria to produce chymosin which was also able to clot milk resulting in cheese curds. The first genetically modified food that approved for release and came into the market was the Flavr Savr tomato in 1994 which was engineered to have extended shelf-life by inserting an antisense gene that delayed ripening (Clive, 1996 and Weasel, 2009). This tomato was not a commercial success, probably due to lack of consumer acceptance, and was eventually withdrawn from the market. Then followed genetically modified crops like potato, Bt. maize, Bt cotton, glyphosphate tolerant soybeans and golden rice in the year 2000 (James, 2011).

Genetic engineering technologies are very controversial with respect to their use (good or bad) particularly in agriculture. Paul Berg did the right thing in 1972 to initiate the formulation of guidelines for research using recombinant DNA techniques. The goal of genetic modification is to add one or more new traits that are not already found in that organism. Creation of genetically modified organisms requires recombinant DNA. Recombinant DNA is a combination of DNA from different organisms or different locations in a given genome that would not normally be found in nature. The genetic engineering techniques involve sophisticated manipulations of genetic material and other biologically important chemicals. Genetic engineering has unprecedented ability to shuffle genes 
which means that genetic engineers can concoct gene combinations that would never be found in nature. The world has come to realize the miracles of genetic engineering in almost every walk of life.

Crop varieties which have been developed using genetic engineering techniques are commonly known as genetically modified organisms. Genetic engineering allows the transfer of one specific gene or a set of genes within a plant family or across genetic lines. The overall goal of genetic engineering is to add a gene that will express a desirable trait in the plant such as resistance to herbicide or resistance to pests. Genetic engineering techniques involve extracting and isolating a specific DNA segment that makes up a gene and inserting it into plant cells. Whole plants are grown from the successfully transformed cells using tissue culture, and then using traditional plant breeding the new gene is transferred into the crop population. Currently there are several crops that have genetically modified for different purposes. These genetically modified varieties include: Corn, soybeans, canola, papaya, cotton, alfalfa, sugar beets, squash and rice. Soybean, canola, sugar beet, alfalfa, and corn genetically modified varieties have been modified for resistance to Roundup (Roundup Ready), field corn, sweet corn and cotton varieties have been modified to contain and express one or more B.t. (Bacillus thuringiensis) genes to make them resistant to some insect pests; papaya and squash have been modified to be resistant to insect vectored viruses (ring spot virus in papaya and squash mosaic virus). Scientists have also developed a genetically modified rice variety (Golden Rice) that is high in vitamin A. The development of disease and insect resistance in plants is the most important application of the transgenic approach (James, 2003).

\subsection{Genetically Modified Crops}

The term genetically modified organism (GMO) refers to the transfer of genes between organisms using a series of laboratory techniques for cloning genes, splicing DNA segments together, and inserting genes into cells. Collectively, these techniques are known as recombinant DNA technology. Plants, animals, cellular microorganisms and viruses have all been genetically modified for several purposes with medicinal, agricultural, environmental (bioremediation) and more recently, industrial applications (Traavik et al., 2007). Genetically modified plants used in agriculture are the largest class of genetically modified organisms intentionally introduced into the environment. Genetically modified crops are grown in varying amounts in select countries, the largest producers being the United States, Canada, Brazil, Argentina and India. The main genetically modified plants for agricultural and industrial processes are maize, soybean, cotton and rapeseed. The main traits introduced are herbicide tolerance (mainly tolerance to glyphosate and glyphosinate) and insecticide tolerance (mainly Bt or Bacillus thuringiensis). Lately there have also been introductions of double and triple-stacked traits (James, 2011).

Genetically modified crop production has been mostly concentrated in industrialized countries (mainly US and Canada). Although industry based data shows the trend of genetically modified crop production shifting to developing countries, the US still holds the majority of the global genetically modified crop production (45\%) (GMO Compass, 2010). Industry-based data also shows a constant increase of areas under genetically modified crop cultivation (GMO Compass, 2010); however, the percentage of global agricultural and arable land occupied with genetically modified crops is still limited (López-Villar et al., 2009). The majority of the top 20 genetically modified-producing countries commit $<1-5 \%$ of their agroecosystems to genetically modified cultivation. Even the world's largest producer, the US, commits no more than about a third of its cropping capacity to genetically modified (Heinemann, 2009a).

\subsection{Basic Steps in Gene Transfer from Crop to Crop for Genetic Modification}

Genetic engineering, on the other hand, employs a very different method to produce improved crops. Instead of relying on sexual recombination to thoroughly stir the parental genes, genetic engineering preserves the integrity of the parental genotype, inserting only a small additional piece of information that controls a specific trait. This is done by splicing a well characterized chunk of foreign DNA containing a known gene into a chromosome of the host species using "restriction" enzymes. Restriction enzymes cut the long DNA strand that makes up a chromosome at very specific places and in a very repeatable way, so that foreign DNA fragments, cut out with the same restriction enzyme, can be inserted and integrated into the host chromosome at the restriction site. There are many different restriction enzymes in use today, each recognizing specific, but different, sites in DNA molecules, providing great versatility in snipping out and inserting specific genes. Restriction 
enzymes are also employed in the sophisticated biochemical procedures that engineer the foreign gene, enabling the host organism to recognize the new information and use it at the proper time, in the proper cellular location, and to the proper extent. Basic genetic engineering takes donor DNA from one organism of cell and places it into the DNA of another organism of cell. The procedure includes following steps:

i) Isolation of Gene: The gene for producing a protein is isolated from a cell. The gene is on the DNA in a chromosome. Special DNA cutting proteins are used to cut out certain sections of DNA. The gene or DNA that is desired is isolated using restriction enzymes. Both the desired gene and a plasmid are treated with the same restriction enzyme to produce identical sticky ends. The gene can be isolated and then copied so that many genes are available to work with.

ii) Preparation of Target DNA: In 1973, two scientists named Boyer and Cohen developed a way to put DNA from one organism into the DNA of bacteria. This process is called recombinant DNA technology. First, a circular piece of DNA called a plasmid is removed from a bacterial cell. Special proteins are used to cut the plasmid ring to open it

iii) Insertion of DNA into Plasmid: The host DNA that produces the wanted protein is inserted into the opened plasmid DNA ring. Then special cell proteins help close the plasmid ring.

iv) Insertion of Plasmid Back into Cell: The circular plasmid DNA that now contains the host gene is inserted back into a bacteria cell. The plasmid is a natural part of the bacteria cell. The bacteria cell now has a gene in it that is from a different organism, even from a human. This is what is called recombinant DNA technology.

v) Plasmid Multiplication: The plasmid that was inserted into the bacteria cell can multiply to make several copies of the wanted gene. Now the gene can be turned on in the cell to make proteins.

vi) Target Cells Reproduction: Many recombined plasmids are inserted into many bacteria cells. While they live, the bacteria's cell processes turn on the inserted gene and the protein is produced in the cell. When the bacterial cells reproduce by dividing, the inserted gene is also reproduced in the newly created cells.

vii) Cells Produced Proteins: The protein that is produced can be purified and used for a medicine, industrial, agricultural, or other uses.

\subsection{Methods of Gene Transfer in Plants}

When desired genes are not found in a particular species or even in its wild relatives and land races, desirable gene cannot be introduced through conventional hybridization. In this situation, desirable genes are introduced from unrelated species through recombinant DNA technology to overcome the genetic barriers. Foreign genes are transferred to crop plants using different transformation tools like gene gun or particle bombardment, electroporation, floral dip (direct transformation methods), and Agrobacterium mediated transformation (in direct transformation methods). The discovery of the ability of agrobacterium tumefaciens to transfer its T-DNA to its host has been utilized for transformation by biologists and it is the method used extensively for transformation. This approach has been used by plant breeders to introduce entirely new genes in plants and the organisms with foreign genes are called genetically modified organisms. There are two types of effective gene transfer to plants, the first is based on the use of Agrobacterium as a biological vector and the second is based on the use of physical, electrical or chemical treatments to introduce isolated DNA into cells alleviating the need for vector use. The latter techniques are commonly termed direct gene transfer methods. Agrobacterium tumefaciens is a plant-pathogenic bacterium that has the ability to transfer a portion of its own genetic information into many plant species through a process called transformation, thereby causing the crown gall disease. This natural plant transformation agent has been modified by molecular geneticists in ways that enable it to move any engineered gene into host plants, without the associated disease symptoms.

\subsubsection{Indirect Gene Transfer Using Agrobacterium as Vector}

The most widely used method for the introduction of new genes into plants is based on the natural DNA transfer capacity of agrobacterium tumefaciens. In nature this soil bacterium causes tumor formation (called crown gall) on a large number of dicotyledonous plant species. During this infection 
a part of the Ti-plasmid of agrobacterium, called T-DNA, is transferred and integrated into the plant genome. This natural capacity made us use this bacterium as a natural vector of foreign genes (inserted into the Ti-plasmid) into plant chromosomes. Agrobacterium-based and direct gene transfer techniques were developed in parallel, but the former is today the most widely-used method because of its simplicity and efficiency in many plants, although it still suffers limitations in terms of the range of species which are amenable to transformation (May et al., 1995). These limitations are due to the natural host range of agrobacterium, which generally infects herbaceous dicotyledonous species most efficiently and is less effective on monocotyledonous and woody species (De Cleene and De Ley, 1976). In these plants, direct gene transfer techniques offer the means to establish transformation systems but many of these techniques suffer from a relatively low efficiency of transformation.

Attempts are therefore being made to exploit and adapt the relatively simple and convenient agrobacterium system to transform recalcitrant plant species. Recent developments indicate that these host-range limitations can be overcome by developing specific plant cell culture procedures and defining inoculation and co-cultivation conditions (Park et al., 1996). The development of reliable transformation protocols for recalcitrant species depends on the establishment of an efficient regeneration procedure, a high transformation rate of the regenerable cells, and an effective selection for regenerating transformed cells (Gheysen et al., 1998). The plant genotype is an important factor, which determines both the regeneration capacity and the efficiency of agrobacterium transformation. The agrobacterium transformation methods are using two different procedures.

The first one is transformation that is dependent on a regeneration procedure while the second is not. The purpose of the regeneration procedure is twofold: It allows the recovery of uniformly transformed shoots and the selection of such shoots. For many plant species, the lack of suitable regeneration method is one of the main bottlenecks in developing a transforming procedure. A particular regeneration method is usually transgenic crops: recent developments and prospects. Only efficient with a limited number of genotypes even within a species. Somaclonal variation may also be problematic with some regeneration procedures. Therefore, many efforts have been devoted to the development of regeneration-independent transformation procedures, such as meristem transformation and in plant transformation techniques. The shoot apex has been used in meristem transformation as an attractive target for transformation since it contains the meristematic cells from which all the aerial parts of the plant are derived.

Because meristems are multicellular organs, primary Transformants are expected to be chimeric, consisting of transformed and untransformed sectors. This has two important consequences. First, it does not always result in germline transformation and transmission of the transgenes to the offspring and second, a stringent selection procedure cannot be applied (Gheysen et al., 1998). These have as a result this transformation method to be labor intensive and very inefficient. Several reports clearly give evidence for stable transformation that has been achieved through meristem transformation with Agrobacterium infection of important crops, such as Musa acuminate (May et al., 1995), Oryza sativa. Oryza sativa is the first cereal species that has been stably transformed via Agrobacterium. Targeting cells of meristem for transformation has, therefore, the advantage that transformed cell lineages, can be obtained without the involvement of a regeneration pathway which involves dedifferentiation and reorganization of cells, so soma clonal variation is not a problem and the transformation is rather genotype-independent.

These are the main advantages of an approach like that. Nevertheless, additional manipulations (Example: hormonal treatments) are necessary to obtain transformants with acceptable frequencies, reintroducing a factor of genotype dependence in the procedure (Gheysen et al., 1998). Over the last decade, several in plant methods for Agrobacterium-mediated transformation of Arabidopsis thaliana have been developed that do not involve any tissue culture steps. In the first described procedure (Feldmann and Marks, 1987) imbibed seeds are infected with Agrobacterium, allowed to grow into mature plants and finally transformants were identified among the seeds harvested from these plants. Bechtold et al. (1995) inoculated flowering A. thaliana plants by vacuum infiltration with an agrobacterium suspension and managed to get transformants at even higher frequencies. Another technique which has been developed recently (Clough and Bent, 1998) is floral dip. It is a simple dipping of developing floral tissues into an Agrobacterium suspension. The absence of any tissue culture step (so soma clonal variation does not occur), the simplicity and the relatively high efficiency 
of the transformation procedure would make such techniques attractive to adapt the technique to other plant species, recalcitrant to regeneration procedure.

\subsubsection{Direct Gene Transfer}

The development of novel direct gene transfer methodology, by-passing limitations imposed by Agrobacterium-host specificity and cell culture constraints, has allowed the engineering of almost all major crops, including formerly recalcitrant cereals, legumes and woody species. Direct gene transfer transformation methods are species and genotype-independent in terms of DNA delivery, but their efficiency is influenced by the type of target cell, and their utility for the production of transgenic plants in most cases depends on the ease of regeneration from the targeted cells, as most methods operate on cells cultured in vitro. As direct gene transfer referred methods such as particle bombardment, DNA uptake into protoplasts, treatment of protoplasts with DNA in the presence of polyvalent cations, fusion of protoplasts with bacterial spheroplasts, fusion of protoplasts with liposomes containing foreign DNA, electroporation-induced DNA uptake into intact cells and tissues, silicon carbide fiber-induced DNA uptake, ultrasound-induced DNA uptake, microinjection of tissues and cells, electrophoretic DNA transfer, exogenous DNA application and imbibition, macroinjection of DNA (Barcelo and Lazzeri, 1998). Most workers in transgenic plant research are interested primarily in applying a transformation technique rather than in its mechanism of operation, so there is a general wish for technically simple methods which are easily transferred between laboratories and which ideally do not require expensive, specialized equipment.

Of the above direct gene transfer techniques, particle bombardment and protoplast transformation are today the most widely used. The former most closely satisfies the criteria of technical simplicity and reproducibility, although it requires a specialized particle gun, the commercial version of which uses relatively expensive consumables. Protoplast transformation can be highly efficient, but demands more complicated cell culture techniques and is limited by the difficulty of regenerating plants. Tissue electroporation is relatively simple, applicable to regenerable tissues and has produced stably transformed plants in several systems after only a relatively short period of development. These results suggest the method should receive further attention to evaluate its potential for wider application. Ultrasound and silicon carbide fiber-mediated techniques are newer methods, which are again technically quite simple. They have been tested in few laboratories and need more research to determine their limitations. Microinjection and laser-mediated transformation are specialized techniques, which are at present inefficient. Electrophoretic transfer to date does not give us evidence that the gene transfer actually occurs. Whole-plant direct gene transfer methods would be methods of choice for most users, but despite several claims of high transformation efficiencies most critical studies have not produced evidence for integrative transformation (Barcelo and Lazzeri, 1998).

\subsection{Advantages of Genetically Modified Crops}

Understanding of the molecular mechanisms of heredity, progress in molecular biology and the possibilities offered by the genetic engineering are all great achievements of science of the last century. These discoveries have stirred up hopes for solving the mystery of life and hopes that soon tools will be found for correcting the nature and mounding it to our needs. Genetic modifications have primarily focused on highly demanded crops for resistance to pathogens, insects and herbicides for better nutrient profiles. The global area under transgenic crops increased 40 times during 1996 to 2003, i.e. an increase from 1.7 million ha to 67.7 million ha was observed (James, 2003).

\subsubsection{Transgenic Approach for Disease Resistance}

For disease resistance, candidate genes are those involved in plant microbe interaction and limit the virulence traits of the pathogens. Example, pathogen cell wall degrading enzymes and toxins. Such genes are introduced to plants that enhance the production of plant defense molecules like saponins, ROS, phytoalexin, and antimicrobial peptides. These are antimicrobial proteins that confer resistance to pathogens by attacking their virulence factors. Such gene introductions by transgenic approach confer resistance to plants against different diseases (Strange, 2005). In rice, the afp gene of Aspergillus giganteus was introduced whose product AFP protein is an antifungal compound. This gene showed stable integration and was inherited by the next generations. This provided resistance against Magnaporthe grisea fungus, which caused rice blast disease (Coca et al., 2004). Wheat transformed with a viral gene encoding KP4 protein conferred 10\%-30\% resistance against Ustilago 
maydis causing wheat smut (Schlaich et al., 2007). Similarly, the thionin gene transferred in rice from oats provided resistance against Burkholderiap lantarii (Iwai et al., 2002). Sugarcane transformation by detoxifying agents degraded toxins and provided resistance against various pathogens (Zhang et al., 1999). A synthetic peptide named D4E1 was introduced in cotton and poplar, providing resistance against Thielaviopsis basicola fungus in cotton (Rajasekaran et al., 2008) and some bacteria in poplar (Montesinos, 2007). Apple was transformed with a grapevine gene stilbene synthase that codes for a phytoalexin, namely resveratrol, found in grapevine but absent in apples. Apple pathogens were unable to degrade the resveratrol due to the absence of any mechanism for this purpose. Resveratrol presence in transgenic apple was confirmed by chemical analysis. This conferred resistance against fungal pathogens (Szankowski et al., 2003). Sometimes, R genes are transformed to a new species or even genus to activate a general resistance mechanism in crop plants. An R gene, Vf, was transferred from wild apple (Malus floribunda) to Malus domesticate, cultivated apples, which conferred resistance against Venturia inaequalis (Belfanti et al., 2004). A maize based $\mathrm{R}$ gene Rxo1 was transformed to rice that conferred resistance against bacterial blight of rice caused by Xanthomonas oryzae (Zhao et al., 2005). However, $\mathrm{R}$ gene transfer between closely related species gives better results (Ayliffe et al., 2004). Rpi-blb2, an NB-LRR R-gene, was transformed to cultivated potato type from wild potato type Solanum bulbocastanum, providing resistance against an Oomycete, Phytophthora infestans (Vander Vossen et al. 2005). In this way, various resistance genes can be transferred to crop plants during independent events, which may provide horizontal resistance to crop plants.

Disease resistance by transgenic approach can also be achieved in crop plants by introducing such genes that activate the plant signaling pathways on pathogen infections, making them resistant to various pathogens simultaneously. The NIM1 or NPR1 gene is a very important part of signaling pathways against several diseases in Arabidopsis thaliana and over-expression of this gene in transformed wheat conferred resistance against Fusarium graminearu (Makandar et al., 2006). Similarly, rice transgenic having NH1 gene, an NPR1 gene orthologue, provided resistance against Xanthomonas oryzae pv Oryzae causing bacterial leaf blight disease in rice (Chern et al., 2005). Various transgenic crops transformed with the AtNPR1 gene have been developed that have resistance against various pathogens. Such plants include grapefruit resistant to Xanthomonas citri subsp. citri (Zhang et al., 2010); cotton resistant to Fusarium oxysporum f.sp. vasinfectum and nematodes (Parkhi et al., 2010); carrot resistant to Botrytis cinerea, Alternaria radicina, and Xanthomonas hortorum (Wally et al., 2009); tomato resistant to Stemphylium solani, F. oxysporum, and X. campestris (Lin et al., 2004); rice resistant to Xanthomonas oryzae and Fusarium verticillioides (Quilis et al., 2008); and tobacco resistant to Meloidogyne incognita (Priya et al., 2011). Tobacco mosaic virus (TMV) causes the leaves of some important crop plants to wither and die. Incorporation into the plant of a gene that encodes the coat protein of the virus protects it from disease (Clark et al., 1995). More progress in development of disease resistant transgenic plants will be seen in the near future.

\subsubsection{Transgenic Approach for Insect Resistance}

One of the most important traits that have been improved through the transgenic approach is insect resistance. Transfer of insecticidal protein coding genes present in Bacillus thuringiensis (a gram positive, naturally occurring soil-borne bacterium) to crop plants has conferred resistance against chewing type insects. Crops transformed with Bacillus thuringiensis based genes are termed Bt crops and $\mathrm{Bt}$ cotton, maize, and eggplant are the most noteworthy examples of such transgenic crops. These transgenic plants produce toxic proteins that damage the insect gut region, resulting in insect death. This also lowers the cost of production of crops as no sprays of pesticides/insecticides to kill chewing Lepidoptera insects are required. Kumar et al. (2008) reported additional benefits of Bt crops that included higher yield due to no or less damage to crop due to chewing insects, and their environment friendliness and hygienic nature as compared to insecticides that pollute the environment due to toxic residues of insecticides on edible plant parts. Bt-cotton transformed with the cry1Ac gene was grown in a field for years and still even soil did not show traces of Bt toxins, showing their environmentally friendly nature (Head et al., 2002).

These benefits resulted in wide acceptance of Bt crops by farmers despite the concerns shown by some people about their bio-safety (Sabir et al., 2011). Bt crops transformed with a Bacillus thuringiensis gene have been used in many regions of the world over the past 30 years after the 
development of Bt corn in the mid 1980's. Lepidopteran pests of various crops including vegetable and food crops are controlled by this transgenic approach. Bt genes have even been useful against beetles, black flies, and nuisance mosquitoes. The higher efficacy of its toxic proteins has made them an integral part of IPM procedures. Five major classes of Bt (cry) genes are cry1, cry2, cry3, cry4, and cyt1. Cry 1 and cry 2 are useful against Lepidoptera, cry3 provides resistance against Coleoptera (beetles), and cry 4 and cyt1 develop resistance against Diptera (mosquitoes and black flies). These toxins are not contact toxins but have to be eaten by the insect along with plant parts.

Most of the toxins have a core portion about half the toxin size that digests the mid gut of the insect, resulting in insect death. In the USA, the CrylAc gene has been transferred into cotton to make it tolerant to the tobacco budworm, CrylAb was engineered in corn to provide resistance against the European corn borer (Ostrinia nubilalis), and potatoes were cloned with the Cry3A gene to check the population of the Colorado potato beetle (Federici, 1998). Bt eggplant made by 'Event EE-1' produces crystalline (Cry) protein toxin expressed in all plants and confers resistance to eggplant against insects (Hanur, 2011). Zhang et al. (2000) reported the Bt gene cryIA provided resistance against chewing insects when cotton was transformed with this gene. Such insect resistance has also been developed in B. rapa from B. napus by transferring the crylc gene (Zhu et al., 2004).

\subsubsection{Transgenic Approach for Herbicide Tolerance}

Engineering herbicide tolerance in transgenic plants has been accomplished exploiting at least three different mechanisms: overexpression of the target enzyme, modification of the target enzyme, and herbicide detoxification (Tsaftaris, 1996). Examples of transgenic plants developed based on each mechanism are following. Glyphosate is an environmentally more benign, widely used broadspectrum herbicide. It is easily degraded in the agricultural environment and works by interfering with the EPSPS enzyme system that is present only in plants. Unfortunately, the herbicide kills crop plants as well as weeds. Transgenic plants including maize, soybean, and cotton have been developed, overexpressing an additional copy of the EPSPS gene from Petunia hybrida under the strong 35S promoter and exhibiting increased tolerance to glyphosate. Alternatively, expression of a mutant Aro A gene from Salmonella typhimurium (which encodes EPSPS) in transgenic tobacco resulted in even higher tolerance to the herbicide than overexpression of the wild-type petunia EPSPS gene (Tsaftaris, 1996). This allows farmers to control weeds in transgenic cultivars spraying with glyphosate alone. A different approach has been applied for development of resistance to the herbicide phosphinothricin (basta). The bar gene from Streptomyces hygroscopicus or S. uiridochromogenes encodes the enzyme phosphinothricin acetyl transferase (PAT), which converts the herbicide to a nontoxic acetylated form. Expression of the bar gene in transgenic tobacco, potato, and tomato plants conferred phosphinothricin resistance at up to 10 times the normal application rate of the herbicide in the field (Wohlleben et al., 1988).

\subsubsection{Transgenic Approach for Product Quality}

Transgenic technologies have been used to modify other important characteristics of plants such as starch composition in potato (Tahaka et al., 1998), ripening in tomato (Klee et al., 1991), lignin content in arabidopsis (Ni et al., 1994), flower vase-life in carnation (Bovy et al., 1995) and explore many new possibilities for uses in agriculture as well as in industry.

\subsubsection{Transgenic Approach for Drought Tolerance}

The great challenge of food security being faced these days the world-over has directed plant scientists towards gene revolution after green revolution due to advances in biotechnology. The gene revolution, in fact, involves modification of qualitative and quantitative traits in an organism by transferring desired genes from one species to another. This strategy is referred to as the transgenic approach. Transgenic approach is being pursued actively throughout the world to improve traits including tolerance to biotic and abiotic stresses in a number of crops (Ashraf et al., 2008). Some of the transgenic lines so produced for the over-expression of specific traits are Beta vulgaris choline monooxygenase (BvCMO) gene in tobacco for higher accumulation of glycinebetaine in leaves, roots and seeds (Zhang et al., 2008); Choline dehydrogenase (betA) in Zea maize from E. coli for higher accumulation of glycinebetaine (Quan et al., 2004); Arabidopsis thaliana and Oryza sativa 1pyrroline-5-carboxylate synthetase (AtP5CS orOsP5CS) in petunia (Yamada et al., 2005); 1pyrroline5-carboxylate synthetase (P5CS) in wheat (Vendruscolo et al., 2007); Dehydration-responsive 
element-binding protein DREB1A/CBF3 in Tall fescue (Zhao et al., 2007). Thus, manipulation of a number of genes predominantly involved in stress tolerance to transgenic plants seems to be a plausible approach. This will certainly allow pyramiding of desirable traits to achieve considerable advance in crop drought tolerance.

\subsection{Disadvantages of Genetically Modified Crops}

The development of disease and insect resistance in plants is the most important application of the transgenic approach. Although proper bio-safety protocols are followed for genetically modified organism testing, they are considered dangerous due to their unnatural origin. These issues have limited development of the transgenic approach in developed countries, which indirectly affects food security in developing countries, where such innovations are badly needed to ensure food security of the masses. Genetic engineering works primarily through insertion of genetic material, although gene insertion must also be followed up by selection. This insertion process does not occur in nature. A gene gun, a bacterial truck or a chemical or electrical treatment inserts the genetic material into the host plant cell and then, with the help of genetic elements in the construct, this genetic material inserts itself into the chromosomes of the host plant.

Engineers must also insert a promoter gene from a virus as part of the package, to make the inserted gene express itself. This process alone, involving a gene gun or a comparable technique, and a promoter, is profoundly different from conventional breeding, even if the primary goal is only to insert genetic material from the same species. Transgenic plant research depends on the availability of procedures of plant transformation. Despite the fact that the genes being transferred occur naturally in other species, there are unknown consequences to altering the natural state of an organism through foreign gene expression. After all, such alterations can change the organism's metabolism, growth rate, and/or response to external environmental factors. These consequences influence not only the genetically modified organism itself, but also the natural environment in which that organism is allowed to proliferate. Potential health risks to humans include the possibility of exposure to new allergens in genetically modified foods, as well as the transfer of antibiotic-resistant genes to gut flora. Horizontal gene transfer of pesticide, herbicide, or antibiotic resistance to other organisms would not only put humans at risk, but it would also cause ecological imbalances, allowing previously innocuous plants to grow uncontrolled, thus promoting the spread of disease among both plants and animals. Although the possibility of horizontal gene transfer between genetically modified organisms and other organisms cannot be denied, in reality, this risk is considered to be quite low. Horizontal gene transfer occurs naturally at a very low rate and, in most cases, cannot be simulated in an optimized laboratory environment without active modification of the target genome to increase susceptibility (Ma et al., 2003). In contrast, the alarming consequences of vertical gene transfer between genetically modified organisms and their wild-type counterparts have been highlighted by studying transgenic fish released into wild populations of the same species (Muir \& Howard, 1999).

\section{CONCLUSION AND RECOMMENDATION}

Genetic modification is the formation of new combinations of heritable material by the insertion of nucleic acid molecules, produced by whatever means outside the cell, into any virus, bacterial plasmid or other vector system so as to allow their incorporation into a host organism in which they do not naturally occur but in which they are capable of continued propagation. Genetic engineering constitutes the hard core of modern biotechnology. Genetically modified organisms (GMOs) are one of the most widespread and controversial products of modern biotechnology. The advances in recombinant DNA technology had occurred in parallel with the development of genetic processes and biological variations. Recombinant DNA is artificially created from two or more DNA incorporated into a single molecule. Genetic engineering, recombinant DNA technology, genetic modification or manipulation and gene splicing are terms that are applied to the direct manipulation of an organism's gene. Genetically modified foods have the potential to solve many of the world's hunger and malnutrition problems and to help protect and preserve the environment by increasing yield and reducing reliance upon chemical pesticides and herbicides. Yet there are many challenges ahead especially in the areas of safety testing, regulation, international policy and food labeling. Many people feel that genetic engineering is the inevitable wave of the future and that we cannot afford to ignore a technology that has such enormous potential benefits. However, we must proceed with 
caution to avoid causing unintended harm to human health and the environment as a result of our enthusiasm for this powerful technology.

Genetically modified crops can mitigate several current challenges in commercial agriculture. Current market trends project is one of the fastest growing and innovative global industries, which not only benefit growers but also consumers and major country economies. However, it is imperative that the agricultural industry and science community invest in better science communication and regulation to tackle unethical research and misinformation. Imperfections and major genetically modified technology can also be combated by stricter regulation, monitoring and implementation by government agriculture bodies, a globally improved risk mitigation strategy and communication with growers, therefore ensuring greater acceptance. With key innovation in precision gene-integration technologies and emerging research in biofortification and stress tolerance, genetically modified crops are forecasted to bring productivity and profitability.

The development of recombinant DNA technology (rDNA technology) permitting the transfer of genetic material between widely divergent species has opened a new era of research into the structure and function of the genome. Generally, the world population has topped 7 billion people and is predicted to double in the next 30 years. Ensuring an adequate food supply for this booming population is going to be a major challenge in the years to come. To meet growing need of ever increasing human population, we need to enhance food production for sustaining food supply. Genetically modified foods promise to meet this need in a number of ways. Some of them are: Pest resistance, herbicide tolerance, disease resistance, cold tolerance, drought tolerance, salinity tolerance and nutritional improvement. The integration of conventional plant breeding with various biotechnological techniques advance crop genetic improvement and shortening the crop improvement cycle with desirable traits in order to satisfy the demand of people in both quantitative and qualitative.

\section{REFERENCES}

[1] Ashraf, M., Athar, H.R., Harris, P.J.C. and Kwon, T.R., 2008. Some prospective strategies for improving crop salt tolerance. Advances in agronomy, 97: 45-110.

[2] Barcelo, P. and Lazzeri, P.A., 1998. Direct gene transfer: chemical, electrical and physical methods. Transgenic plant research, 35-55.

[3] Bechtold, N. and Bouchez, D., 1995. In planta Agrobacterium-mediated transformation of adult Arabidopsis thaliana plants by vacuum infiltration. In Gene transfer to plants 19- 23.

[4] Begna, T., Challenges and Progresses of Molecular Plant Breeding in Crop Improvement.

[5] Belfanti, E., Silfverberg-Dilworth, E., Tartarini, S., Patocchi, A., Barbieri, M., Zhu, J., Vinatzer, B.A., Gianfranceschi, L., Gessler, C. and Sansavini, S., 2004. The HcrVf2 gene from a wild apple confers scab resistance to a transgenic cultivated variety. Proceedings of the National Academy of Sciences, 101(3): 886890.

[6] Bovy, A.G., Van Altvorst, A.C., Angenent, G.C. and Dons, J.J.M., 1995, June. Genetic modification of the vase-life of carnation. In VI International Symposium on Postharvest Physiology of Ornamental Plants 405:179-189.

[7] Christou, P., 1995. Strategies for variety-independent genetic transformation of important cereals, legumes and woody species utilizing particle bombardment. Euphytica, 85:13-27.

[8] Clark, D.O., Von, M.K., Saunders, K., Baluch, W.M. and Simon, G.E., 1995. A chronic disease score with empirically derived weights. Medical care, 33(8): 783-795.

[9] Clough, S.J. and Bent, A.F., 1998. Floral dip: a simplified method for Agrobacterium-mediated transformation of Arabidopsis thaliana. The plant journal, 16(6):735-743.

[10] Coca, M., Bortolotti, C., Rufat, M., Penas, G., Eritja, R., Tharreau, D., Del Pozo, A.M., Messeguer, J. and San Segundo, B., 2004. Transgenic rice plants expressing the antifungal AFP protein from Aspergillus giganteus show enhanced resistance to the rice blast fungus Magnaporthe grisea. Plant Molecular Biology, 54(2): 245-259.

[11]Compass, G.M.O., 2010. Genetically modified plants: Global cultivation area. Maize. Updated to March, 29, 2010.

[12] De Cleene, M. and De Ley, J., 1976. The host range of crown gall. The Botanical Review, 42(4): 389-466.

[13]Delaney, B., 2015. Safety assessment of foods from genetically modified crops in countries with developing economies. Food and Chemical Toxicology, 86: 132-143. 
[14]Feldmann, K.A., Marks, M.D., Christianson, M.L. and Quatrano, R.S., 1989. A dwarf mutant of Arabidopsis generated by T-DNA insertion mutagenesis. Science, 243(4896): 1351-1354.

[15] Gheysen, D., Willems, L., Grimonpont, C., Kerkhofs, P., Capiau, C,Conrath, K., Roussef, R., Mamoun, R., Portetelle, D., Burny, A. and Adam, E., 1998. Phosphorylation of bovine leukemia virus Tax protein is required for in vitro transformation but not for transactivation. Oncogene, 16(17): 2165-2176.

[16] Gruhn, P., Goletti, F. and Yudelman, M., 2000. Integrated nutrient management, soil fertility, and sustainable agriculture: current issues and future challenges.

[17] Hanur, V.S., 2011. Bt resistance in Helicoverpa species: Indian policy needs urgent revision. Current Science, 101(4): 470-471.

[18] Head, G., Surber, J.B., Watson, J.A., Martin, J.W. and Duan, J.J., 2002. No detection of Cry1 Ac protein in soil after multiple years of transgenic Bt cotton (Bollgard) use. Environmental Entomology, 31(1): 30-36.

[19] Heinemann, J.A., 2009. Hope not hype: The future of agriculture guided by the international assessment of agricultural knowledge, science, and technology for development.

[20] Iwai, M., Harada, Y., Tanaka, S., Muramatsu, A., Mori, T., Kashima, K., Imanishi, J. and Mazda, O., 2002. Polyethylenimine-mediated suicide gene transfer induces a therapeutic effect for hepatocellular carcinoma in vivo by using an Epstein-Barr virus-based plasmid vector. Biochemical and biophysical research communications, 291(1): 48-54.

[21]Jackson, D.A., Symons, R.H. and Berg, P., 1972. Biochemical method for inserting new genetic information into DNA of Simian Virus 40: circular SV40 DNA molecules containing lambda phage genes and the galactose operon of Escherichia coli. Proceedings of the National Academy of Sciences, 69(10): 2904-2909.

[22] James, C., 2011. Global status of commercialized biotech/GM crops, 44.

[23] James, M.G., Denyer, K. and Myers, A.M., 2003. Starch synthesis in the cereal endosperm. Current opinion in plant biology, 6(3): 215-222.

[24] Klee, H.J., Hayford, M.B., Kretzmer, K.A., Barry, G.F. and Kishore, G.M., 1991. Control of ethylene synthesis by expression of a bacterial enzyme in transgenic tomato plants. The Plant Cell, 3(11): 11871193.

[25] Kumar, S., Chandra, A. and Pandey, K.C., 2008. Bacillus thuringiensis (Bt) transgenic crop: an environment friendly insect-pest management strategy. J Environ Biol, 29(5): 641- 653.

[26] Lawlor, D.W., 2013. Genetic engineering to improve plant performance under drought: physiological evaluation of achievements, limitations, and possibilities. Journal of experimental botany, 64(1): 83- 108.

[27]Lee, Y.J., Yi, H., Kim, W.J., Kang, K., Yun, D.S., Strano, M.S., Ceder, G. and Belcher, A.M., 2009. Fabricating genetically engineered high-power lithium-ion batteries using multiple virus genes. Science, 324(5930): 1051-1055.

[28]Leser, S., 2013. The 2013 FAO report on dietary protein quality evaluation in human nutrition: Recommendations and implications. Nutrition Bulletin, 38(4): 421- 428.

[29] Lin, Q., Yuan, M., Zhou, Y.A.N., Li, X., Xiao, J. and Wang, S., 2004. A paralog of the MtN3/saliva family recessively confers race-specific resistance to Xanthomonas oryzae in rice. Plant, cell \& environment, 34(11): 1958-1969.

[30] Lopez-Villar, O., Garcia, J.L., Sanchez-Guijo, F.M., Robledo, C., Villarón, E.M., Hernandez-Campo, P., Lopez-Holgado, N., Diez-Campelo, M., Barbado, M.V., Perez-Simon, J.A. and Hernandez-Rivas, J.M., 2009. Both expanded and uncultured mesenchymal stem cells from MDS patients are genomically abnormal, showing a specific genetic profile for the 5q- syndrome. Leukemia, 23(4): 664- 672.

[31] Makandar, R., Essig, J.S., Schapaugh, M.A., Trick, H.N. and Shah, J., 2006. Genetically engineered resistance to Fusarium head blight in wheat by expression of Arabidopsis NPR1. Molecular Plant-Microbe Interactions, 19(2): 123-129.

[32] May, G.D., Afza, R., Mason, H.S., Wiecko, A., Novak, F.J. and Arntzen, C.J., 1995. Generation of transgenic banana (Musa acuminata) plants via Agrobacterium-mediated transformation. Bio/technology, 13(5), 486-492.

[33] Montesinos, E., 2007. Antimicrobial peptides and plant disease control. FEMS microbiology letters, 270(1): $1-11$.

[34] Muir, W.M. and Howard, R.D., 1999. Possible ecological risks of transgenic organism release when transgenes affect mating success: sexual selection and the Trojan gene hypothesis. Proceedings of the National Academy of Sciences, 96(24): 13853-13856.

[35] Ni, W., Jung, H.J.G., Chapple, C.C.S. and Meyer, K., 1994. Impact of lignin composition on cell-wall degradability in an Arabidopsis mutant. Journal of the Science of Food and Agriculture, 79(6): 922-928. 
[36] Parkhi, V., Kumar, V., Campbell, L.M., Bell, A.A., Shah, J. and Rathore, K.S., 2010. Resistance against various fungal pathogens and reniform nematode in transgenic cotton plants expressing Arabidopsis NPR1. Transgenic research, 19(6): 959-975.

[37] Priya, D.B., Somasekhar, N., Prasad, J.S. and Kirti, P.B., 2011. Transgenic tobacco plants constitutively expressing Arabidopsis NPR1 show enhanced resistance to root-knot nematode, Meloidogyne incognita. BMC research notes, 4(1), 231.

[38] Quan, R., Shang, M., Zhang, H., Zhao, Y. and Zhang, J., 2004. Engineering of enhanced glycine betaine synthesis improves drought tolerance in maize. Plant Biotechnology Journal, 2(6): 477- 486.

[39] Quilis, J., Penas, G., Messeguer, J., Brugidou, C. and Segundo, B.S., 2008. The Arabidopsis AtNPR1 inversely modulates defense responses against fungal, bacterial, or viral pathogens while conferring hypersensitivity to abiotic stresses in transgenic rice. Molecular Plant-Microbe Interactions, 21(9): 12151231.

[40] Rajasekaran, K., Cary, J.W., Cotty, P.J. and Cleveland, T.E., 2008. Development of a GFP-expressing Aspergillus flavus strain to study fungal invasion, colonization, and resistance in cottonseed. Mycopathologia, 165(2): 89-97.

[41] Sabir, H.M., Tahir, S.H. and Khan, M.B., 2011. Bt cotton and its impact on cropping pattern in Punjab. Pak J Soc Sci, 31(1): 127-134.

[42] Schlaich, T., Urbaniak, B., Plissonnier, M.L., Malgras, N. and Sautter, C., 2007. Exploration and swiss field-testing of a viral gene for specific quantitative resistance against smuts and bunts in wheat. In Green Gene Technology, 97-112.

[43] Ssekyewa, C. and Muwanga, M.K., 2009. Biotechnology in Organic Agriculture in Africa: Myth or Oversight. Journal of Science and Sustainable Development, 2(1): 33-38.

[44] Strange, R.N. and Scott, P.R., 2005. Plant disease: a threat to global food security. Annual review of phytopathology, 43.

[45] Szankowski, I., Briviba, K., Fleschhut, J., Schönherr, J., Jacobsen, H.J. and Kiesecker, H., 2003. Transformation of apple with the stilbene synthase gene from grapevine (Vitis vinifera L.) and a PGIP gene from kiwi (Actinidia deliciosa). Plant Cell Reports, 22(2): 141-149.

[46] Takigawa, T., Suda, M., Ogawa, Y., Tanaka, K., Tamura, N., Yasoda, A., Uehira, M., Nishimoto, H., Itoh, H., Saito, Y. and Shiota, K., 1998. Skeletal overgrowth in transgenic mice that overexpress brain natriuretic peptide. Proceedings of the National Academy of Sciences, 95(5): 2337-2342.

[47] Thomas, J.W., Touchman, J.W., Blakesley, R.W., Bouffard, G.G., Beckstrom-Sternberg, S.M., Margulies, E.H., Blanchette, M., Siepel, A.C., Thomas, P.J., McDowell, J.C. and Maskeri, B., 2003. Comparative analyses of multi-species sequences from targeted genomic regions. Nature, 424(6950): 788-793.

[48] Traavik, T. and Heinemann, J., 2007. Genetic engineering and omitted health research: still no answers to ageing questions.

[49] Tsaftaris, A., 1996. The development of herbicide-tolerant transgenic crops. Field Crops Research, 45: 115123.

[50] Van der Vossen, E.A., Gros, J., Sikkema, A., Muskens, M., Wouters, D., Wolters, P., Pereira, A. and Allefs, S., 2005. The Rpi-blb2 gene from Solanum bulbocastanum is a Mi-1 gene homolog conferring broadspectrum late blight resistance in potato. The Plant Journal, 44(2): 208-222.

[51] Vendruscolo, E.C.G., Schuster, I., Pileggi, M., Scapim, C.A., Molinari, H.B.C., Marur, C.J. and Vieira, L.G.E., 2007. Stress-induced synthesis of proline confers tolerance to water deficit in transgenic wheat. Journal of plant physiology, 164(10): 1367-1376.

[52] Wally, O., Jayaraj, J. and Punja, Z.K., 2009. Broad-spectrum disease resistance to necrotrophic and biotrophic pathogens in transgenic carrots (Daucus carota L.) expressing an Arabidopsis NPR1 gene. Planta, 231(1): 131-141.

[53] Wohlleben, W., Arnold, W., Broer, I., Hillemann, D., Strauch, E. and Punier, A., 1988. Nucleotide sequence of the phosphinothricin N-acetyltransferase gene from Streptomyces viridochromogenes Tü494 and its expression in Nicotiana tabacum. Gene, 70(1): 25-37.

[54] Yamada, M., Morishita, H., Urano, K., Shiozaki, N., Yamaguchi-Shinozaki, K., Shinozaki, K. and Yoshiba, Y., 2005. Effects of free proline accumulation in petunias under drought stress. Journal of Experimental Botany, 56(417): 1975-1981.

[55]Zhang, C., Wohlhueter, R. and Zhang, H., 2016. Genetically modified foods: A critical review of their promise and problems. Food Science and Human Wellness, 5(3): 116-123.

[56]Zhang, J., Tan, W., Yang, X.H. and Zhang, H.X., 2008. Plastid-expressed choline monooxygenase gene improves salt and drought tolerance through accumulation of glycine betaine in tobacco. Plant cell reports, 27(6): 1113 . 
[57]Zhang, J.C., Woo, Y.J., Chen, J.A., Swain, J.L. and Sweeney, H.L., 1999. Efficient transmural cardiac gene transfer by intrapericardial injection in neonatal mice. Journal of molecular and cellular cardiology, 31(4): 721-732.

[58]Zhang, X., Munis, M.F.H., Tu, L., Deng, F., Tan, J., Xu, L., Xu, S., Long, L., 2010. A thaumatin-like protein gene involved in cotton fiber secondary cell wall development enhances resistance against Verticillium dahliae and other stresses in transgenic tobacco. Biochemical and biophysical research communications, 393(1): 38-44.

[59]Zhao, J., Ren, W., Zhi, D., Wang, L. and Xia, G., 2007. Arabidopsis DREB1A/CBF3 bestowed transgenic tall fescue increased tolerance to drought stress. Plant Cell Reports, 26(9): 1521-1528.

[60]Zhao, K., Wang, C., Fan, Y., Zheng, C., Qin, T.and Zhang, X., 2014. High-resolution genetic mapping of rice bacterial blight resistance gene Xa23. Molecular genetics and genomics, 289(5): 745-753.

[61]Zhu, S., Walker, D.R., Boerma, H.R., All, J.N. and Parrott, W.A., 2004. Effects of defoliating insect resistance QTLs and a cry1Ac transgene in soybean near-isogenic lines. Theoretical and Applied Genetics, 116(4): 455-463.

Citation: Temesgen Begna, "The Role of Genetically Modified Crops to Agricultural Advancement." International Journal of Research Studies in Agricultural Sciences (IJRSAS), 2020; 6(10), pp. 9-22, https://doi.org/10.20431/2454-6224.0610002

Copyright: (C) 2020 Authors. This is an open-access article distributed under the terms of the Creative Commons Attribution License, which permits unrestricted use, distribution, and reproduction in any medium, provided the original author and source are credited. 